implicated-whether lung, brain, kidney, intestine, etc.; and, again, whether arterial trunk, minute arterial branches, capillaries, or veins. Minute particles of fibrine mingling with the blood may probably go the whole round of the circulation with, of course, a liability to be arrested in any set of capillaries, and thus to become the centre and source of fresh mischief. There is reason to believe, too, that, apart from the mere mechanical results of floating masses of fibrine, fibrinous debris in the blood may have something of a toxic influence, and thus induce febrile excitement with a high temperature.

I cannot conclude without an expression of adniration for the clinical acumen of the late Dr. Kirkes, who was the first in this country to indicate what, in his paper in the Medico-Chirnergical Transactions (vol. xxxv), he calls "some of the principal effects resulting from the detachment of fibrinous deposits from the interior of the heart, and their mixture with the circulating blood." That paper opened out an en tirely new field of pathological and clinical research, the importance of which is yearly becoming more apparent.

\section{NOTES OF A CHOLERA-EPIDEMIC.}

\section{By CHARLES A. BRIGSTOCKE, M.R.C.S., Medical Officer and} Public Vaccinator in the Calne Union.

Although cholera has visited this country as an epidemic three or four times, its cause and means of propagation are still so enveloped in mystery, that all additional statistics may prove of service, however unimportant in themselves.

The cholera-epidemic of I 866 visited the town of Llanelly (where I was engaged in active practice at the time) with great severity, no fewer than two hundred deaths from that cause having occurred in the town and immediate neighbourhood. I am decidedly of opinion that the more than usually fatal character of the scourge in this case may be fairly attributed to the following causes : first, the situation of the town, being in great part built upon marshy badly drained land near the junction of a river with the sea ; and, secondly, the nature of the population, composed chiefly of work-people employed in the various collieries-iron, copper, and tin.works in the town and neighbourhood, with a large percentage fluctuating between pauperism and self-support. When to these unfavourable influences we add the fact that pigs were kept by many of the inhabitants in immediate proximity to their dwelling-houses, it would have been difficult to find a town more favourable to the development of cholera. There was scarcely any wandering epidemic but found a nidus there; while fever was an almost constant resident. It seems only fair to the local authorities to state, that since the visitation of cholera more attention, I believe, has been paid to the improvement of the sanitary condition of the town.

On July 4th, I visited a woman, aged 27 , suffering from severe choleraic diarrhcea; and on the 7 th, the first well marked case of cholera occurred in the district. The epidemic remained apparently quiescent for a short time, but then spread with frightful rapidity. At its acme, from fifteen to twenty-five attacks occurred daily; it then gradually declined, the last death from cholera happening in the early part of October.

During its spread, although it displayed a marked preference for the filthiest localities, yet, as if by exception to prove the rule, one or two of apparently the most healthy parts of the district suffered severely.

The following statistics of 192 cases of cholera, which fell under my own personal observation, may prove interesting.

$$
\text { Cases. }
$$

Deaths.

$$
\begin{aligned}
& \text { Under } 5 \text { years ........24........ } 3 \text { or } 54.16 \text { per cent. } \\
& \text { From } 5 \text { to } 20 \text { years ...33 …... } 9 \text { or } 27.27 \\
& \text {,, } 20 \text { to } 40,, \ldots . .64 \ldots . . . .19 \text { or } 29.68 \\
& , 40 \text { to } 60,, \ldots . .449 \ldots \ldots . .18 \text { or } 36.73 \\
& \text {, } 60 \text { to } 80,, \ldots . .20 \ldots . . . .8 \text { or } 40 \\
& \text {, } 80 \quad,, \ldots \ldots 2 \ldots \ldots . . \text { I or } 50 \\
& \text {,", } \\
& \text { ", } \\
& \text {, , } \\
& \text {, } \\
& \text { Total...192 } \\
& 68 \text { or } 35.4 \mathrm{I} \text { per cent. }
\end{aligned}
$$

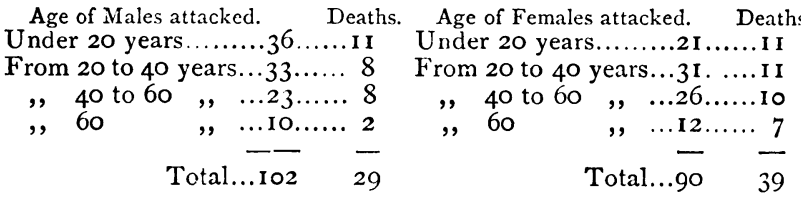

From the above tables it will be seen that, although the disease attacked the series in not very unequal proportion, the deaths were much more numerous in the female sex, the percentage of deaths to attacks being in the case of males 28.43 , and in females $43 \cdot 3$.

With regard to liability of attack; while the infirm and badly fed seemed prone to suffer, intemperance, contrary to general belief, did not appear to materially increase the liability; but, when attacked, those of intemperate habits had a much greater mortality : two of the patients, after recovery from severe choleraic diarrhœea, became intoxicated and sank during the algide stage in a few hours. Parturition occurring during cholera seemed (in the five or six cases which I attended) to produce an increased and favourable effort on nature's part to throw off the disease. One woman delivered of twins, however, sank rapidly, although, even in her case, the improved pulse and temperature gave evidence of the endeavour to rally. I need scarcely add that all the children were still-born. There did not appear any increase to miscarriage or abortions during the epidemic. The symptoms of cholera are so well known that I need not recapitulate them, but I may remark, in passant, that in the cases of three or four children there was very little vomiting or purging present. Severe cramps were the exception, not the rule. Most of those who died in the algide stage retained consciousness to the last; but in the majority of fatal cases occurring among children, convulsions or coma closed the scene ; and, indeed, in the cases above mentioned, where little vomiting or purging was present, coma was present almost from the commencement of the attack, as if the choleraic virus acted narcotically on the system. Consecutive fever of any intensity was met with in but few cases, although two died from the resulting brain-congestion.

With regard to therapeutics in cases of true cholera, no drug seemed of much avail. Those who took medicine, and those who abstained from doing so, seemed to die with great impartiality. One man, who swallowed an ounce of carbonate of soda in mistake for sulphate of magnesia, recovered; another (a very severe case), who drank a quart of beer with brandy in it, rallied from that moment, and attributed his recovery to it. Of those drugs employed, small doses of calomel or of carbonate of soda seemed, if anything, to have a favourable effect. An endeavour to maintain the temperature of the body by means of hot bottles to the axillae, feet, etc., with a supply of cold water to drink, seemed almost all (with one's present knowledge of the therapeutics of this disease) that one could do in the way of remedial measures. I think, considering the passive condition of the system, as evidenced by the suppression of urine, the dry skin, and intolerance of the alimentary canal, it is not surprising that drugs have no effect. Too much stress cannot be laid upon the importance of attending to the diarrhoea by which it is often, but not always, preceded, particularly as it is believed that, during an attack of diarrhœa, the body is more susceptible of the choleraic virus. Of course the diarrhœa may be treated in the ordinary way; but I may remark that, during an epidemic of cholera, it does not yield readily to treatment; and there would appear to be a much greater tendency to disturbed action on the part of the alimentary canal (evidenced by more or less pain), even where actual diarrhœea is not present. Many confirmed smokers were compelled to temporarily abandon the habit, owing to the resulting bowel-disturbance. As little alteration as possible should be made in one's habits, particularly as to diet. The quantity of vegetables and of stimulants taken might perhaps be slightly diminished; but even this would appear to require great care.

It would have been ludicrous, were not the subject such a serious one, to notice the precautions and nostrums so loudly vaunted at this time. Some invariably carried stimulants with them, to which they applied themselves with such industry that the amount of drunkenness was materially increased. Others looked upon spirits of camphor as an infallible means of safety. Among the workpeople, colliers, etc., in particular, whole families were dosed with this remedy, with the effect upon some of the infant children, as may be imagined, of producing symptoms of poisoning. To such an extent did the camphor mania run, that almost any price was given for the drug in the district. But it would be more easy to ridicule such treatment, were the medical pro. fession able to do more towards the reducing of this disease.

With regard to sanitary matters in infected districts, all proper precautions should be taken when cholera is anticipated; but, during its presence, measures of this sort must be very cautiously carried out, lest fresh food be supplied for its propagation. All the ejecta should be carefully and speedily removed, and covered with earth or lime. The water-supply of the district should be particularly looked to. In the Llanelly district, the disease spread rapidly along the course of contaminated water-supplies. Yet so slow are the public to sufficiently estimate the importance of this source of danger, that, in the case referred to, the only means found successful in preventing the use of contaminated water was the emptying loads of lime into the streams.

Measures should also be taken for separating those attacked from those 
free from the disease; and inspectors should be appointed to make daily visits to their respective districts, and report all cases of diarrhœea, etc. Supplies of medicine for the treatment of diarrhœea should be lodged with them, and made readily available to all applicants; and extra allowances in the shape of beef-tea, etc., should be given to those of the poorer classes who might be attacked with diarrhoea.

One important feature deserving of attention was that, during the prevalence of cholera, the cases requiring medical attendance for other forms of disease were very exceptional; it seemed as if this dire epidemic had swallowed up all the minor ills.

\section{ON ANÆSTHETICS.*}

BY THOMAS J ONES, M.D.,

Assistant-Physician to Victoria Hospital for Sick Children; formerly (for eleven years) Resident Medical Officer and Administrator of Anæsthetics to

$$
\text { St. George's Hospital. }
$$

2. Ether was first employed by me as an anæsthetic at St. George's Ilospital in the year 1861. Although it was administered on a large conical sponge (a very objectionable mode), I succeeded in almost all cases in producing the necessary degree of narcotism. It was given for several capital operations, and in cases requiring careful dissection, such as hernix, with complete success. In the following year I discontinued its use, however, in the operating theatre, on account of the inconvenience occasioned to those present by the smell of the vapour, and from the time it took in some cases to get the patient under its influence, which was a very serious objection when several had to be operated upon. I, however, continued its use in cases which were considered unsafe for chloroform, such as those in a state of collapse from severe accidents. The stimulating effects of ether in such cases were attended with remarkably good results : they were generally in a better state after than before the operation.

In a paper read on this subject before St. George's Hospital Medical Society in 1863 , I observed that the result of my experience to that time tended to show (I) that ether caused during the first stage more cerebral excitement than chloroform ; (2) that it produced a greater degree of anæsthesia before the consciousness was completely abolished; (3) that during the stage of very complete unconsciousness, the reflex function of the cerebro-spinal centres was not abolished to the same degree as under chloroform ; (4) that it stimulates instead of depressing the heart.

My subsequent experience confirms, in the main, these conclusions. Ether, unlike chloroform, would seem to exert no paralysing influence on the heart, carried to the extent necessary for the performance of operations. In the paper referred to, I related two cases in which ether was administered with good effect after chloroform had been tried and found to produce dangerous symptoms.

Dr. Snow states (On Ancesthetics, p. 362) that "ether is altogether incapable of causing sudden death by paralysis of the heart, which has caused the accidents which have happened during the administration of chloroform. I have not been able to kill an animal in that manner with ether even when I have made it boil, and administered the vapour almost pure. The heart has continued to beat after the natural breathing has ceased, even when the vapour has been exhibited without air. .

I hold it, therefore, to be almost impossible that a death from this agent can occur in the hands of a medical man who is applying it with ordinary intelligence and attention". When this passage is taken in connection with the fact that Dr. Snow records in the same work no fewer than fifty fatal cases from chloroform, it is very wonderful that he should still persevere in the use of chloroform, especially when we find he observes (op. cit.) that he "usually rendered adult patients insensible in four or five minutes, and children in two or three", and that he "never failed to make the patient insensible in any one instance in which ether was administered". Hence, ether being in his hands perfectly successful and manageable, I cannot help agreeing with the opinion advanced in the leading article in this JouRNAL of the 16 th instant, that he, like every one else, was considerably influenced in the choice of the anæsthetic which he used by the energetic and uncompromising advocacy of the discoverer of chloroform.

I think the disadvantages of ether over chloroform are really very few and trivial. I find that some prefer the flavour of ether-vapour to that of chloroform. Its pungency, when inhaled, only lasts a few seconds, and not at all in some cases, when properly administered. As to the question of cost, I also think this objection has been exaggerated. Methylated washed ether (which answers all purposes quite as well) can be bought for half-a-crown a pound. If the anæsthetic be given

* Continued from page 577 of last number. rapidly and unsparingly at the commencement, I do not think the dose for each patient should cost more than sixpence-so that, in fact, the cost is not much greater than that of chloroform.

With reference to the mode of administration, I think the plan recommenaed by our American friends is as good as any-namely, a thick towel, in half-dozen folds, arranged in the form of a cone. Care should be taken that its base should be large enough to take in the chin and the nose-its shape such as to fit the face accurately. A small sponge should be placed inside, which should be squeezed out of warm water after each case, to prevent its becoming so cold as to interfere with the evaporation of the ether. Mr. Warrington Haward's apparatus, described in this JOURNAL on the 2 nd inst., is also a convenient method of administering it, and answers very well. But I find that the oiled silk, which forms its external layer, is an objection, because it interferes with the conduction of heat from the hand into the interior of the cone. In a cone covered with the oiled silk, the interior becomes so reduced in temperature that the evaporation of the ether is considerably checked.

Thinking that an inhaler would effect, amongst other advantages, considerable saving of the ether, I have had for some time my attention directed to this point, but have not as yet succeeded in suggesting any improvenient upon the one adopted by Dr. Snow.

3. The Combination of Chloroform and Ether.-My experience, in the main, confirms the opinion held by Dr. Snow, that the combination of these two liquids combines the undesirable qualities of both. When the two agents are combined in their liquid state, one never knows what one is about. I should not have considered it necessary to allude to this point, had I not seen a communication from Dr. Edis in the JOURNAL of November I6th, still advocating this method-one which, I thought, had been given up some time since. I have, however, been in the habit for some years past of administering the vapours of these two agents to the same patient with considerable advantage. I begin with chloroform ; but as soon as the pulse shows signs of failure, I commence the administration of ether, and continue its use until the pulse is restored, or as long as the patient remains quiet enough for the performance of the operation. In this manner, I believe, the cases of avoidable deaths from cardiac failure resulting from chloroform might be averted.

4. Nitrous Oxidi:- When I consider the safety, ready applicability, and the pleasantness of this agent, together with the success attending it, I confess I am surprised that surgeons do not adopt it more generally than they do for the minor operations requiring but few minutes in their performance. I have succeeded in keeping the patients under its influence for eight or ten minutes by its reapplication from time to time. I think that for some cases of operations about the eye its use would be invaluable, seeing that it produces no sickness.

\section{NOTE ON THE ADMINISTRATION OF ETHER.} By JOHN COUPER, F.R.C.S.,

Surgeon to and co-Lecturer on Surgery at the Lond nn Hospital ; Senior AssistantSurgeon to the Royal London Ophthalmic Hospital, Moorfields.

SOME years since, ether was repeatedly administered at the London Hospital, with unsatisfactory results. Although it was given in a full dose, complete narcotism was not speedily obtained, and was preceded by excitement and violent agitation of the limbs. The ether then used had not been specially prepared, and in all probability was not anhydrous. Certainly, its effects on these occasions were entirely different from those with which I have since become familiar, when pure anhydrous ether has been employed.

Having repeatedly seen the administration of ether by Dr. Joy Jeffries last August, I have since employed it exclusively, and propose now to state, briefly, the results of this short trial. The chief operations performed have been ovariotomy, lumbar colotomy, amputation through the knee-joint, partial resection of ankle, excision of tumour over the parotid gland, besides many eye operations.

The operations on the eye, for which an anæsthetic is required, demand, with few exceptions, narcotism as profound as can be safely produced. The reflex movements, produced by contact of instruments with the cornea, must cease before the operation begins; and, as a rule, they do not cease until a stage of narcotism, beyond that of insensibility to pain, is reached. I do not now inquire how far this need of profound narcotism explains the fact of a great chloroform mortality in ophthalmic practice. In regard to this point, it should be borne in mind that the number of cases in an eye-hospital requiring an anæsthetic is immensely greater than in a general hospital of equal size, and that a large apparent mortality in the former thus becomes a small death-rate. 